\title{
Surfactant-coated Tea Waste: Preparation, Characterization and its Application for Methylene Blue Adsorption from Aqueous Solution
}

Pirbazari $\mathrm{AE}^{1,2^{*}}$, Pargami NR ${ }^{2}$, Ashja $\mathbf{N}^{2}$ and Emami $\mathrm{MS}^{2}$

${ }^{1}$ Fouman College of Engineering, University of Tehran, Iran

${ }^{2}$ Caspian College of Engineering, University of Tehran, Iran

\begin{abstract}
This paper reports on the development of organo-modified tea waste (TW) adsorbent prepared by using sodium dodecyl sulfate (SDS) for removing methylene blue (MB), a model cationic dye, from aqueous solution. The natural and modified samples were characterized by scanning electron microscope (SEM), nitrogen physisorption and Fourier transform infrared spectroscopy (FT-IR). Batch adsorption experiments were carried out to remove MB from its aqueous solutions using SDS coated TW (SCTW). Analysis of adsorption results obtained at different temperatures showed that the adsorption pattern on the SCTW can be described perfectly with Langmuir isotherm model compared with Freundlich isotherm model. The adsorption process has been found exothermic in nature and thermodynamic parameters have been calculated. The adsorption kinetic followed the pseudo-second order kinetic model. Desorption studies suggest that MB adsorption onto the SCTW should be mainly controlled by the hydrophobic interaction mechanism, along with a considerable contribution of the cationic exchange mechanism.
\end{abstract}

Keywords: Tea waste; Sodium dodecylesulfate; Methylene blue; Isotherm; Kinetic; Mechanism

\section{Introduction}

Water is a source of life and energy, although millions of people worldwide are suffering with the shortage of fresh and clean drinking water. Rapid pace of industrialization, population expansion, and unplanned urbanization have largely contributed to the severe water pollution and surrounding soils. The main sources of freshwater pollution can be attributed to discharge of untreated sanitary and toxic industrial wastes, dumping of industrial effluent, and runoff from agricultural fields. It is well known that $70-80 \%$ of all illnesses in developing countries are related to water contamination, particularly susceptible for women and children. Pollutants discharged in wastewaters can be toxic to aquatic life and cause natural waters to be unfit as potable water sources [1,2].

Dyes are widely used in broad industrial sectors such as textile manufacturing, leather tanning, cosmetics, paper, food processing, and pharmaceutical industries. The annual production of synthetic dyes and dying stuffs are generally exceeding 700,000 tones as reported in the literature [3-5]. In addition, more than 10,000 various types of dyes are available according to the reported color index (CI) by the Society of Dyers and Colorists as well as the American Association of Textile Chemists and Colorists [6]. Generally, more than 100,000 commercial dyes are produced every year for the sake of industrial applications [7]. About $2-50 \%$ of the dyestuffs quantity is released into the ecosystem as generated industrial wastewater due to various applications of basic and reactive dyes. However, this subject represents a major environmental problem due to environmental impact on the quality of water [8]. Methylene blue (MB) is the most commonly used substance for dying cotton, wood and silk. It can cause eye burns which may be responsible for permanent injury to the eyes of human and animals. Although MB is seen in some medical uses in large quantities, it can also be widely used in coloring paper, dyeing cottons, wools, coating for paper stocks, etc. Though MB is not strongly hazardous, it can cause some harmful effects. Acute exposure to MB will cause increased heart rate, vomiting, shock, Heinz body formation, cyanosis, jaundice and quadriplegia and tissue necrosis in humans [9].

Treatment of textile effluent nowadays requires an efficient methodology to face the current challenges. However, several industrial wastewater treatment methodologies and technologies are well known and commonly used for removal and purification of water from organic dyes. These include coagulation, floatation, oxidation, ozonization and nanofiltration as well as biological treatment [3]. On the other hand, adsorption is known as one of the effective methodology for removal of organic and inorganic pollutants and dyes from water matrices [10]. Adsorption technique affords also greater flexibility in the design of the aimed adsorbent for the target pollutant as well as ease and high operational flexibility. In addition, efficiency and superiority of the adsorption technique are mainly relying on the possible harmless of the treated water [11]. Since the performance of an adsorptive separation is directly dependent on the quality and cost-effectiveness of the adsorbent, the last decade has seen continuous improvement in the development of effective adsorbents in the form of activated carbon [12], zeolites [13], clay minerals [14], chitosan [15], lignocelluloses [16], natural minerals [17] and functionalized polymers [18]. However, most of these adsorbents are either not effective (due to diffusion limitation or the lack of active surface sites) or have shown problems like high cost, difficulties of separation from wastewater, or generation of secondary wastes.

The methods to treat dyeing wastewater can be classified in to two types: physical and chemical processes. Among all these methods, adsorption by activated carbon is the most common process for dye removal from wastewater. Although, the process is highly effective, the running costs are high with the need for regeneration after each

*Corresponding author: Azadeh Ebrahimian Pirbazari, Fouman College of Engineering, University of Tehran, P.O. Box 43515-1155, Fouman 43516-66456, Iran, Tel: 98133 4734927; E-mail: aebrahimian@ut.ac.ir

Received June 19, 2015; Accepted July 21, 2015; Published July 24, 2015

Citation: Pirbazari AE, Pargami NR, Ashja N, Emami MS (2015) Surfactant-coated Tea Waste: Preparation, Characterization and its Application for Methylene Blue Adsorption from Aqueous Solution. J Environ Anal Toxicol 5: 310. doi:10.4172/2161 0525.1000310

Copyright: (c) 2015 Pirbazari AE, et al. This is an open-access article distributed under the terms of the Creative Commons Attribution License, which permits unrestricted use, distribution, and reproduction in any medium, provided the original author and source are credited. 
sorption cycle [19]. This has led to the search for other potentially suitable alternative, that is more economical and equally an effective materials for dye removal by adsorption [20]. Recently, comparative studies of cationic and anionic dye adsorption by agricultural solid wastes and some other low-cost adsorbents were reported [3,21-23]. Some of the advantages of using agricultural waste for wastewater treatment include simple technique, requires little processing, good adsorption capacity, selective of adsorption effluent, low cost, free availability and easy regeneration [3]. Besides, the exhausted adsorbents can be disposed of by burning and the heat used for steam generation [24]. However, the application of untreated agricultural or plant waste as adsorbents can also bring several problems such as low adsorption capacity, high chemical oxygen demand (COD) and biological oxygen demand (BOD) as well as total organic carbon (TOC) due to release of soluble organic compounds contained in the plant wastes [25]. Therefore, the agricultural wastes need to be treated or modified before being used as adsorbent. Tea is consumed by the largest number of people in the world and considered the second most popular beverage in the world. Only water is rated higher in world consumption than tea. It is estimated that somewhere between 18 and 20 billion cups of tea are drunk daily on our planet. Canned or bottled tea drinks as well as instant tea drinks are produced on industrial scale by hot water extraction of tea leaves, and the producers face a problem in disposing of the spent tea leaves after the extraction. Hence, the utilization of such waste is most desirable [26].

Surfactant molecules are composed of both hydrophilic and hydrophobic moieties and extensively used in various industrial processes such as textiles, pulp, and paper industry as well as our daily life. Surfactant-dye associations are important in various dyeing processes such as textiles dyeing, photography, and pharmaceuticals processes [27]. Surfactants play a useful role in the textile dying processes due to their general action as leveling, dispersing and wetting agents. Therefore, surfactants are considered as ideal and suitable components in the textile processing which requires liquid that quickly and uniformly wets the fiber surface. The surfactants act mostly in two ways, either by formation of a complex species with ionic dyes or adsorption into the fiber [28].

In recent years, the use of surfactants in water and wastewater treatment has been specially preferred to separation of metal ions and other toxic substances [8,29-33]. To the best of our knowledge, the application of sodium dodecyl sulfate (SDS) coated tea waste for methylene blue $(\mathrm{MB})$ removal from aqueous environment has not been reported so far. The aim of this study is to present and investigate an efficient methodology to face the current challenges for color treatment of industrial textile wastewater effluent by using a chemically designed and modified adsorbent based on tea waste immobilized anionic surfactant, sodium dodecyl sulfate (SDS), for the adsorptive removal of methylene blue (MB) as an example of cationic dyes. Optimization of all experimental controlling factors and conditions such as reaction contact time, $\mathrm{pH}$, adsorbent dosage, initial dye concentration, mechanism of adsorption as well as temperatures were also explored and evaluated.

\section{Experimental}

\section{Materials}

The tea waste was collected from Faculty of Fouman Cafeteria. The collected materials were washed several times with boiled water and finally with distilled water to remove any adhering dirt. The washed materials were then dried in the oven at $60^{\circ} \mathrm{C}$ for $48 \mathrm{~h}$. The dried tea waste was then ground and sieved into a size range of $100-500 \mu \mathrm{m}$. Finally, the resulting product was stored in air- tight container for further use. The methylene blue (MB) purchased from Merck (No.115943) (purity 99.99\% and its very low $\mathrm{pK}_{\mathrm{a}}$ value (less than 1), was selected as are presentative reactive dye for this study. The MB structure is shown in Scheme 1. A stock solution of MB was prepared by dissolving $1.0 \mathrm{~g}$ of $\mathrm{MB}$ in $1 \mathrm{~L}$ of deionized water, and the concentrations of $\mathrm{MB}$ used (50-500 mg/L) were obtained by dilution of the stock solution. The $\mathrm{pH}$ of the solution was adjusted to the desired value by adding a small quantity of $0.01 \mathrm{M} \mathrm{HCl}$ or $0.01 \mathrm{M} \mathrm{NaOH}$. Sodium dodecyl sulfate (SDS) solutions were prepared from commercially available product (Merck, 8.22050) dissolved in distilled water.

\section{Prepared SDS-coated tea waste (SCTW) and characterization}

The solution of SDS was prepared below its critical micellar concentration $(\mathrm{CMC}=0.0082 \mathrm{M})$, as beyond CMC the surface modification was not effective. $100 \mathrm{~mL}$ of $2 \times 10^{-3} \mathrm{M}$ SDS solution was treated with $10.0 \mathrm{~g}$ often waste and shaken in a temperature controlled shaker at $180 \mathrm{rpm}$ for $3 \mathrm{~h}$ at $303 \mathrm{~K}$. The SDS-coated tea waste (SCTW) was then filtered and washed with deionized water till conductance of filtrate was less than $0.05 \mu \mathrm{S}$. The SCTW was then dried in hot air oven at $80^{\circ} \mathrm{C}$ for $24 \mathrm{~h}$. This was then stored in air tight container for further use.

Fourier transform infrared (FTIR) analysis was applied to determine the surface functional groups, using FTIR spectroscope (FTIR-2000,Bruker), where the spectra were recorded from 4000 to $400 \mathrm{~cm}^{-1}$. Surface morphology was studied using Scanning Electron Microscopy (Vegall-TescanCompany). Specific surface area based on nitrogen physisorption was measured by Sibata surface area apparatus 1100 . The samples were degassed at $100^{\circ} \mathrm{C}$ for $2 \mathrm{~h}$ prior to the sorption measurement.

\section{Adsorption procedure}

Equilibrium isotherms were determined by shaking a fixed mass of SCTW $(0.4 \mathrm{~g})$ with $100 \mathrm{~mL}$ of MB solutions with different initial concentrations $(50,100,200,300,400$ and $500 \mathrm{mg} / \mathrm{L})$ in $250 \mathrm{~mL}$ glass Erlenmeyer's flasks at a temperature of $20^{\circ} \mathrm{C}$ and $\mathrm{pH}=7$. The procedure was repeated for temperatures 30,40 and $50^{\circ} \mathrm{C}$. Initial $\mathrm{pH}$ adjustments were carried out by adding either a $0.01 \mathrm{M}$ hydrochloric acid or 0.01 $\mathrm{M}$ sodium hydroxide solution. After shaking the flasks at $180 \mathrm{rpm}$ for $2 \mathrm{~h}$, small aliquots $(2 \mathrm{~mL})$ were withdrawn and centrifuged to remove the adsorbent particles., and then this aliquot was analyzed for the remaining $\mathrm{MB}$ concentrations with spectrometry at the wavelength of maximum absorbance, $664 \mathrm{~nm}$ using a double beam UV-Vis spectrophotometer (Shimadzu, Model UV2100,Japan).

\section{Kinetic studies}

Adsorption kinetics experiments were performed by contacting

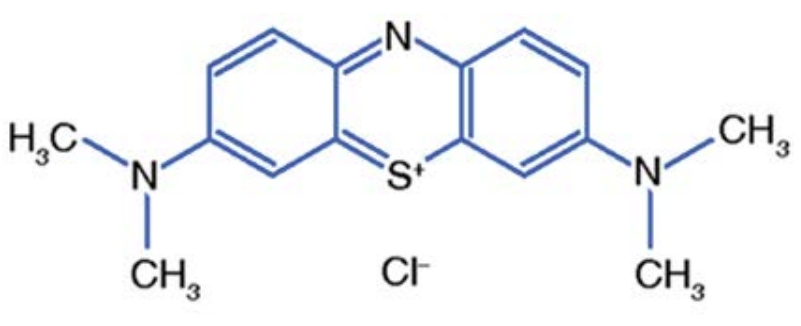

Scheme 1:The structure of Methylene Blue (MB). 
Citation: Pirbazari AE, Pargami NR, Ashja N, Emami MS (2015) Surfactant-coated Tea Waste: Preparation, Characterization and its Application for Methylene Blue Adsorption from Aqueous Solution. J Environ Anal Toxicol 5: 310. doi:10.4172/2161-0525.1000310

Page 3 of 11

$200 \mathrm{~mL} \mathrm{MB}$ solution of different initial concentrations ranging from 50 to $200 \mathrm{mg} / \mathrm{L}$ with $0.8 \mathrm{~g}$ SCTW in a $500 \mathrm{~mL}$ stopper red conical flask at room temperature. At fixed time intervals, the samples were taken from the solution and were analyzed. During the kinetic studies, we controlled the $\mathrm{pH}$ value at 7 .

\section{Isotherm modeling}

The non-linear forms of the Langmuir and Freundlich, isotherm models were used to analyze the equilibrium isotherm data [34]. The fitness of these models was evaluated by the non-linear coefficients of determination $\left(\mathrm{R}^{2}\right)$. The Matlab (version7.3) software package was used for the computing. The Langmuir adsorption isotherm assumes that adsorption takes place at specific homogeneous sites within the adsorbent and has found successful application form any processes of monolayer adsorption. The Langmuir isotherm can be written in the form:

$$
q_{e}=\left(Q_{\max } K_{L} C_{e}\right) /\left(1+K_{L} C_{e}\right)
$$

Where $\mathrm{q}_{\mathrm{e}}$ is the adsorbed amount of the dye, $\mathrm{C}_{\mathrm{e}}$ is the equilibrium concentration of the dye in solution, $\mathrm{Q}_{\max }$ is the monolayer adsorption capacity and $\mathrm{K}_{\mathrm{L}}$ is Langmuir adsorption constant. The Freundlich isotherm is an empirical equation which assumes that the adsorption occurs on heterogeneous surfaces. The Freundlich equation can be expressed as:

$$
q_{e}=K_{F} C_{e}^{1 / n}
$$

Where $\mathrm{K}_{\mathrm{F}}$ and $1 / \mathrm{n}$ are fitting constants which can be regarded roughly, the capacity and strength of adsorption, respectively.

\section{Kinetic models}

The Lagergren rate equation [35] is one of the most widely used adsorption rate equations for the adsorption of solute from a liquid solution. The pseudo-first-order kinetic model of Lagergren may be represented by:

$$
d q / q_{e}-q=k_{1} d t
$$

Integrating this equation for the boundary conditions $t=0$ to $t=t$ and $\mathrm{q}=0$ to $\mathrm{q}=\mathrm{q}_{\mathrm{t}}$, gives:

$$
\ln \left(q_{e}-q_{t}\right)=\ln q_{e}-k_{1} t
$$

Where $\mathrm{q}_{\mathrm{e}}$ and $\mathrm{q}_{\mathrm{t}}$ are the amounts of adsorbate $(\mathrm{mg} / \mathrm{g})$ at equilibrium and at time $\mathrm{t}(\mathrm{min})$, respectively, and $\mathrm{k}_{1}$ is the rate constant of pseudofirst-order adsorption $\left(\mathrm{min}^{-1}\right)$. The validity of the model can be checked by linearized plot of $\ln \left(\mathrm{q}_{\mathrm{e}}-\mathrm{q}_{\mathrm{t}}\right)$ versus $\mathrm{t}$. Also, the rate constant of pseudofirst-order adsorption is determined from the slope of the plot.

The pseudo-second-order equation based on adsorption equilibrium capacity can be expressed as:

$$
d q /\left(q_{e}-q_{t}\right)^{2}=k_{2} d t
$$

Taking into account, the boundary conditions $\mathrm{t}=0$ to $\mathrm{t}=\mathrm{t}$ and $\mathrm{q}=0$ to $\mathrm{q}=\mathrm{q}_{\mathrm{t}}$, the integrated linear form the above equation can be rearranged to follow equation:

$$
t / q_{t}=1 / k_{2} q_{e}^{2}+t / q_{e}
$$

Rearranging the variables gives the following equation:

$t / q_{t}=1 / k_{2} q_{e}^{2}+t / q_{e}$

Where the theoretical equilibrium adsorption capacity $\left(\mathrm{q}_{\mathrm{e}}\right)$ and the second-order constants $\mathrm{k}_{2}\left(\mathrm{~g} \mathrm{mg}^{-1} \mathrm{~min}^{-1}\right)$ can be determined experimentally from the slope and intercept of plot $t / q_{t}$ versus $t$.

\section{Statistical analysis}

All experiments were performed in duplicate and the mean values were presented. The data were analyzed by one-way analysis of variance (ANOVA) using SPSS11.5 for Windows. The data was considered statistically different from control at $\mathrm{P}<0.05$.

\section{Studies on point zero charge $\left(\mathrm{pH}_{\mathrm{pzc}}\right)$}

In $\mathrm{pH}_{\mathrm{pzc}}$ determination, $0.01 \mathrm{M} \mathrm{NaCl}$ was prepared and its $\mathrm{pH}$ was adjusted in the range of $2-11$ by adding $0.01 \mathrm{M} \mathrm{NaOH}$ or $\mathrm{HCl}$. Then, $50 \mathrm{~mL}$ of $0.01 \mathrm{M} \mathrm{NaCl}$ each was put in conical flask and then $0.1 \mathrm{~g}$ of the SCTW was added to these solutions. These flasks were kept for $72 \mathrm{~h}$ and final $\mathrm{pH}$ of the solution was measured by using $\mathrm{pH}$ meter. Graphs were then plotted for $\mathrm{pH}_{\text {final }}$ versus $\mathrm{pH}_{\text {initial }}$.

\section{Results and Discussion}

\section{FTIR spectral analysis}

A closer insight into the biomass surface properties was obtained by comparing the FTIR spectra of prepared samples (Figure 1) in the range of $400-4000 \mathrm{~cm}^{-1}$. FTIR spectra of tea waste (TW), SDS-coated tea waste (SCTW) and SCTW after MB adsorption are shown in Figure 1. In FTIR spectrum of TW (Figure 1a), the broad and intense absorption peaks at around $3400 \mathrm{~cm}^{-1}$ correspond to the $\mathrm{O}-\mathrm{H}$ stretching vibrations due to inter- and intra-molecular hydrogen bonding of polymeric compounds (macromolecular associations), such as alcohols, phenols and carboxylic acids, as in pectin, cellulose and lignin, thus, showing the presence of "free" hydroxyl groups on the adsorbent surface [36]. The peak at $2919 \mathrm{~cm}^{-1}$ is attributed to the symmetric and asymmetric $\mathrm{C}-\mathrm{H}$ stretching vibration of aliphatic acids [36]. The precursor had $\mathrm{C}=\mathrm{O}$ stretching of aldehyde group peaks located on $1709 \mathrm{~cm}^{-1}$ [37]. The peak at $1624 \mathrm{~cm}^{-1}$ is due to asymmetric stretching vibrations of $\mathrm{C}=$ Oand the

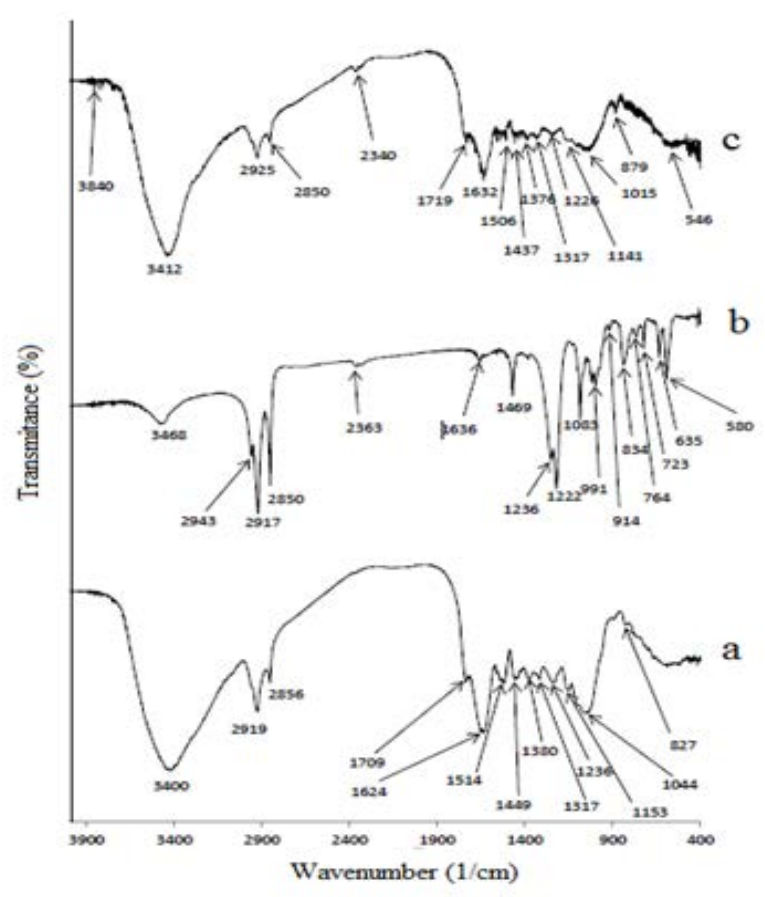

Figure 1:FTIR spectra of a) TW b) SCTW and c) SCTW after MB adsorption 
peaks observed at 1514 and $1449 \mathrm{~cm}^{-1}$ can be assigned to $\mathrm{C}=\mathrm{C}$ vibration in aromatic rings. The other prominent peaks are due to $\mathrm{NH}_{2}, \mathrm{C}=\mathrm{O}$ and $-\mathrm{C}-\mathrm{C}-\left(1449,1044\right.$ and $827 \mathrm{~cm}^{-1}$, respectively) groups. The assigned peaks at $600-1000 \mathrm{~cm}^{-1}$ may be related to the $=\mathrm{C}-\mathrm{H}$ of alkenes. It is clear from these peaks that the adsorbent has many functional groups. Most probably, these functional groups are responsible for adsorption via hydrogen bonding with MB. FT-IR spectrum of the SCTW (Figure 1b) shows more intense vibrations compare to TW at 2943, 2917 and $2850 \mathrm{~cm}^{-1}$ assigned to the $-\mathrm{CH}_{2}$ group from SDS and the peak observed at $1236 \mathrm{~cm}^{-1}$ could be assigned to $-\mathrm{SO}_{3}$ stretching vibration., and these suggest that the SDS have been successfully coated the surface of TW. However, the FT-IR spectra of SCTW and SCTW after MB adsorption were found to exhibit similar functional groups due to the domination of the functional groups of TW in this sorbent as the major component in these materials.

\section{Nitrogen physisorption and SEM analysis}

The specific surface area of TW and SCTW based on nitrogen physisorption were determined by Brunauer-Emmett-Teller (BET) theory. It was found that the surface area of TW and SCTW were 22 and $45 \mathrm{~m}^{2} \mathrm{~g}^{-1}$, respectively. As Nadeem et al. reported [38], anionic (SDS) and cationic (CTAB) surfactant enhanced the characteristics of adsorbent better than the nonionic one (Triton X-100). The enhancement can be attributed to the typical properties of micelle formation, adsorption, wetting and solubilization. Being amphipathic in nature, surfactant-modified surfaces can offer enhanced surface area and wetting (water or oil wet) according to the requirement because surfactant molecules are capable of organizing themselves accordingly. Moreover, the presence of electrostatic interactions facilitates the possibility for selective adsorption as well. In mechanism section, we will give details about the role of surfactant in MB adsorption. SEM images of TW, SCTW and SCTW after MB adsorption with two magnifications are presented in Figure 2. It is evident from the obtained SEM images that surfactant modification is significantly responsible to alter the physico-chemical properties of the materials. Figure 2a shows that the TW possesses a rough surface morphology with some pores. The SCTW appear to possess more homogenous surfaces and well organized porous structure than the TW (Figure 2b). The surface of SCTW after MB adsorption(Figure 2c), however, shows that the pores of tea waste are covered with MB molecules.

\section{Effect of initial concentration and contact time on MB adsorption}

Figure 3 shows the effect of the initial dye concentration (50-200 $\mathrm{mg} / \mathrm{L}$ ) on the adsorption of MB. It was observed that amount of MB adsorbed was rapid for the first $20 \mathrm{~min}$ and there after it proceeded at a slower rate (20-80 min) and finally reached saturation. The equilibrium adsorption increases from 15.54 to $61.50 \mathrm{mg} / \mathrm{g}$, with increase in the initial MB concentration from 50 to $200 \mathrm{mg} / \mathrm{L}$. The findings are because as the initial concentration increases, the mass transfer driving force becomes larger, hence resulting in higher MB adsorption [39]. It is also shown in Figure 3 that the contact time needed for MB solutions with initial concentrations of 50-200 mg/L to reach equilibrium was 80 $\mathrm{min}$. The initial concentration provides an important driving force to overcome all mass transfer resistances of the MB between the aqueous and solid phase. However, the experimental data were measured at 120 min to be sure that full equilibrium was attained.

\section{Point of zero charge $\left(\mathrm{pH}_{\mathrm{pzc}}\right)$ studies and the effect of $\mathrm{pH}$ on MB adsorption}

The point of zero charge $\left(\mathrm{pH}_{\mathrm{p}}\right)$ is an important factor that determines the linear range of $\mathrm{pH}$ sensitivity and then indicates the type of surface active centers and the adsorption ability of the surface [40]. Many researchers studied the point of zero charge of adsorbents that prepared from agricultural solid wastes in order to better understand of adsorption mechanism. Cationicdye adsorption is favored at $\mathrm{pH}>\mathrm{pH}_{\mathrm{prc}}$, due to presence of functional groups such as $\mathrm{OH}^{-}, \mathrm{COO}^{-}$groups. Anionic dye adsorption is favored at $\mathrm{pH}<\mathrm{pH}_{\mathrm{pzc}}$ where the surface becomes positively charged $[41,42]$. The graph of $\mathrm{pH}_{\text {final }} \mathrm{vs}^{\mathrm{pH}} \mathrm{intial}_{\text {ial }}$ was plotted as shown in Figure 4. The intersections of the curves with the straight line are known as the end points of the $\mathrm{pH}_{\mathrm{prc}}$ and this value is 6.3 for SCTW. Figure 5 shows the effect of $\mathrm{pH}$ on the adsorption of MB. The experiments were conducted at $50 \mathrm{~mL}$ of initial MB concentration, $0.10 \mathrm{~g}$ SCTW dose. It was observed that $\mathrm{pH}$ gives a significant influence to the adsorption process. $\mathrm{MB}$ is cationic dye, which exists in aqueous solution in the form of positively charged ions $\left(\mathrm{MB}^{+}\right)$. As a charged species, the degree of its adsorption onto the adsorbent surface is primarily influenced bythe surface charge on the adsorbent, which inturn is influenced by the solution $\mathrm{pH}$. As shown in Figure 5, the removal percentage was minimum at $\mathrm{pH} 2$ (42\%), this increased up to 6 and remained nearly constant (93\%) over the initial $\mathrm{pH}$ ranges of $6-12$. This phenomenon occurred due to the presence of excess $\mathrm{H}^{+}$ions in the adsorbate and the negatively charged surface adsorbent. Lower adsorption of $\mathrm{MB}$ at acidic $\mathrm{pH}\left(\mathrm{pH}<\mathrm{pH}_{\mathrm{pzc}}\right)$ is due to the presence of excess $\mathrm{H}^{+}$ions competing with the cation groups on the dye for adsorption sites. At higher solution $\mathrm{pH}\left(\mathrm{pH}>\mathrm{pH}_{\mathrm{pzc}}\right)$, the SCTW possibly negatively charged and enhance the positively charged dye cations through electrostatic forces of attraction. We selected $\mathrm{pH}=7$ for adsorption and kinetic experiments.

\section{Effect of adsorbent dose}

Adsorbent dose is an important parameter that strongly influences the adsorption process by affecting the adsorption capacity of the adsorbent [43]. Therefore, the influence of adsorbent dose on $\mathrm{MB}$ adsorption by SCTW was investigated in the range of 0.05-0.6 g/100 $\mathrm{mL}$ of $\mathrm{MB}$ solution (initial concentration: $100 \mathrm{mg} / \mathrm{L}, \mathrm{pH}=7$ ) (Figure 6). The adsorption efficiency increased from $85 \%$ to $96 \%$ as the adsorbent dose increased from 0.05 to $0.2 \mathrm{~g}$. The increase in the percentage of dye removal with adsorbent dose could be attributed to an increase in the adsorbentsurface area, augmenting the number of adsorption sites available for adsorption, as previously reported [44,45]. The decrease in sorption capacity with increasing dosage of adsorbent at constant dye concentration and volume may be attributed to saturation of adsorption sites due to particulate interaction such asaggregation [46]. Such aggregation would lead to a decrease in total surface area of the adsorbent and an increase in diffusional path length [47]. Therefore, in the following experiments, the adsorbent dose was fixed at $0.2 \mathrm{~g} / 100$ $\mathrm{mL}$.

\section{Mechanism of MB adsorption onto SCTW}

The surface modification and proposed mechanism of $\mathrm{MB}$ adsorption ontoSCTW is shown schematically in Figure 7. In oxides, generally, a monolayer of surfactant molecules (which is called hemimicelles) is formed with the surfactant head group facing toward the oxide surface and its hydrocarbon tail groups into solution. In the event that higher concentrations of the surfactant molecules are presented in the solution, new hydrophobic interactions between hydrocarbons tail-groups will be occurred which results in the 
Citation: Pirbazari AE, Pargami NR, Ashja N, Emami MS (2015) Surfactant-coated Tea Waste: Preparation, Characterization and its Application for Methylene Blue Adsorption from Aqueous Solution. J Environ Anal Toxicol 5: 310. doi:10.4172/2161-0525.1000310
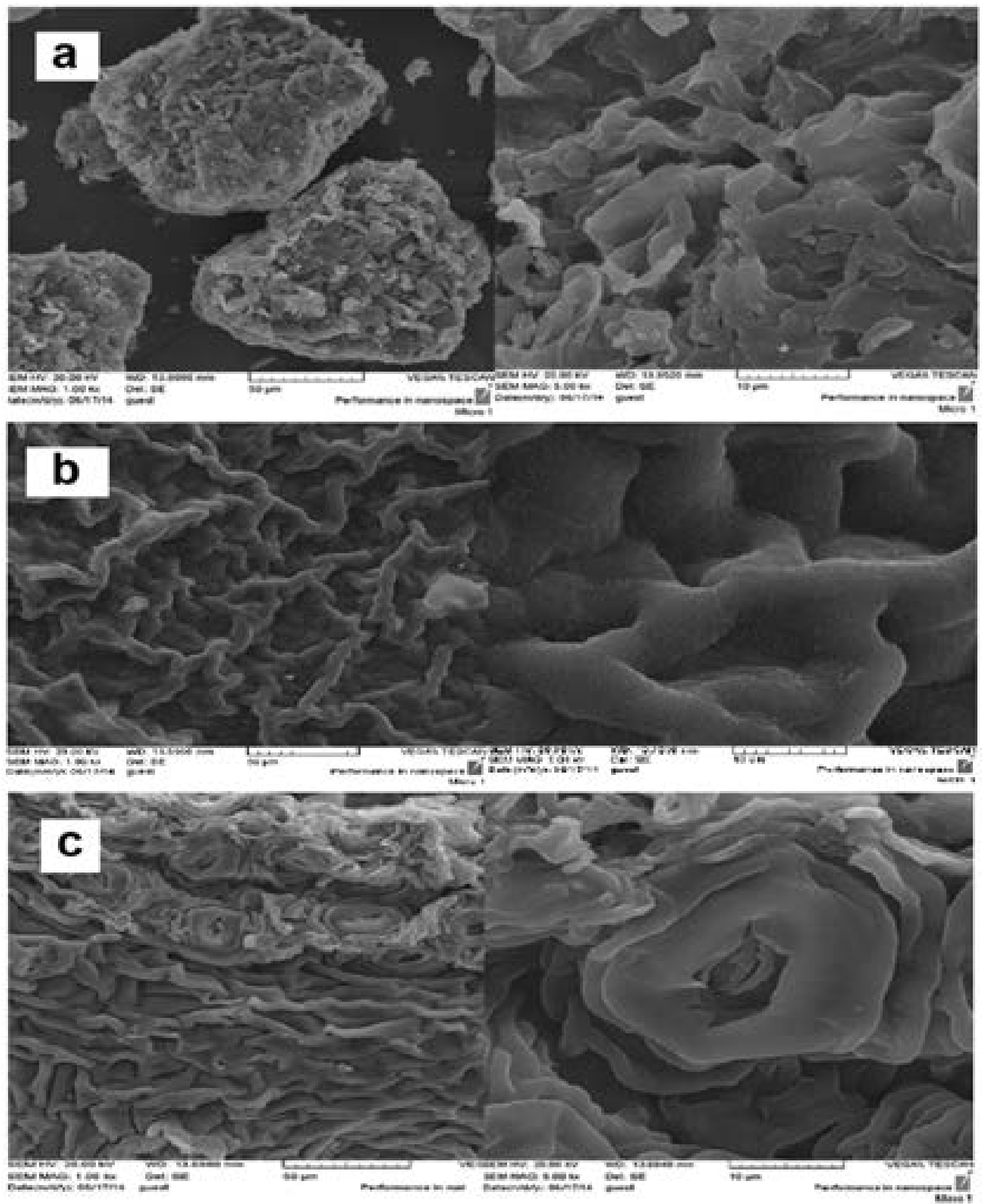

Figure 2: SEM images of a) TW b) SCTW and c) SCTW after MB adsorption. 


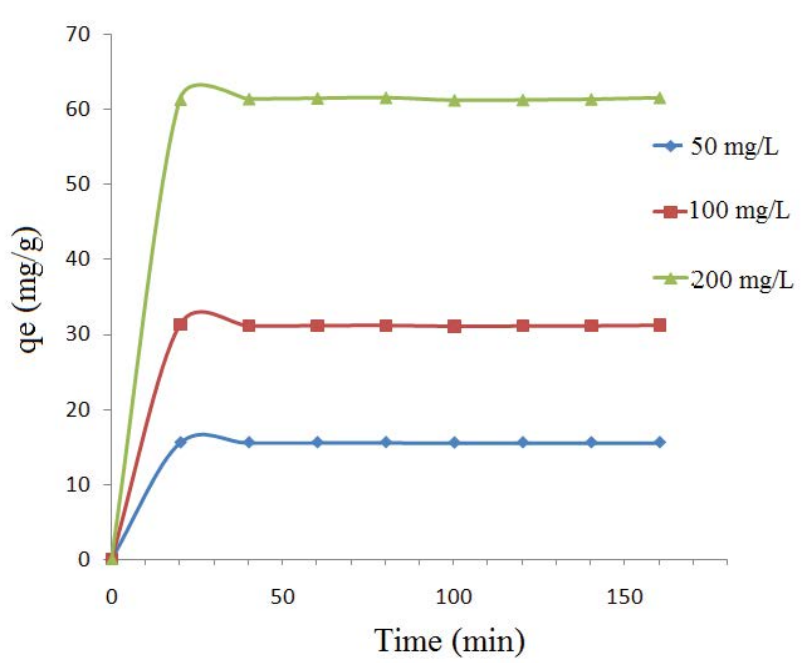

Figure 3: Effect of contact time and initial concentration $(50-200 \mathrm{mg} / \mathrm{L})$ on the adsorption of MB on SCTW (dosage $=0.4 \mathrm{~g} / 100 \mathrm{~mL}$ and temperature= $298 \mathrm{~K})$.

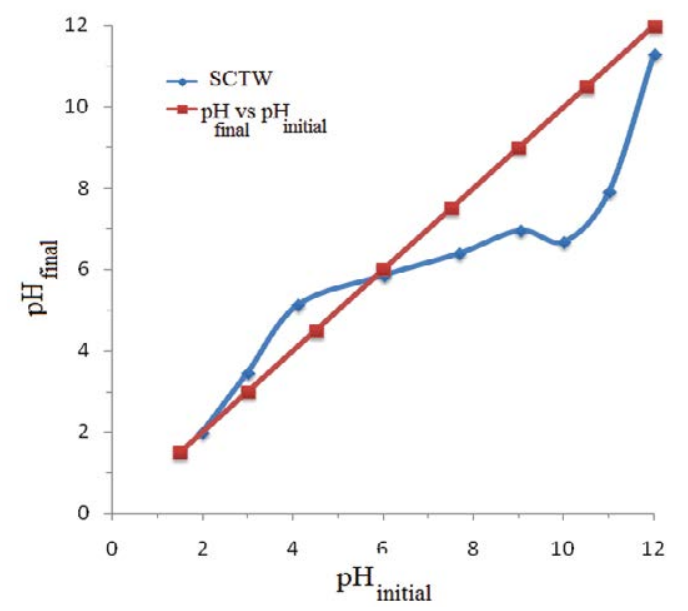

Figure 4: Plot for determination of point of zero charge of SCTW.

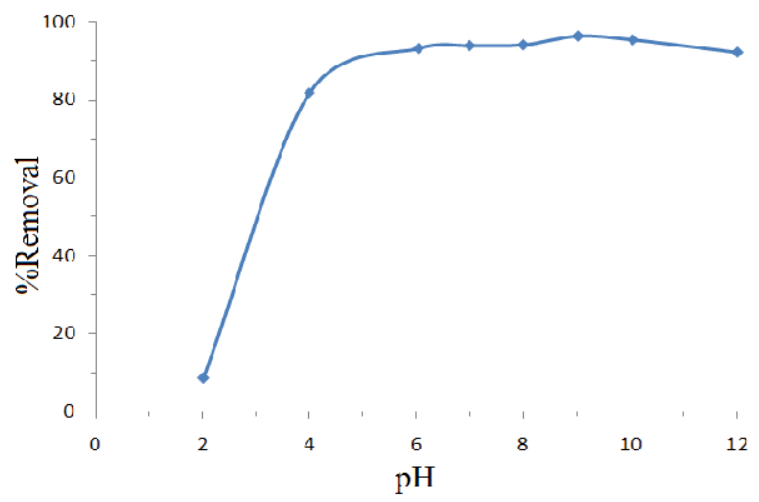

Figure 5: Effect of $\mathrm{pH}$ on adsorption of $\mathrm{MB}(\mathrm{pH}: 2-12$; initial $\mathrm{MB}$ concentration: $100 \mathrm{mg} / \mathrm{L}$; contact time:120 min; SCTW dosage: $0.4 \mathrm{~g} / 100 \mathrm{~mL}$; temperature: 298K).

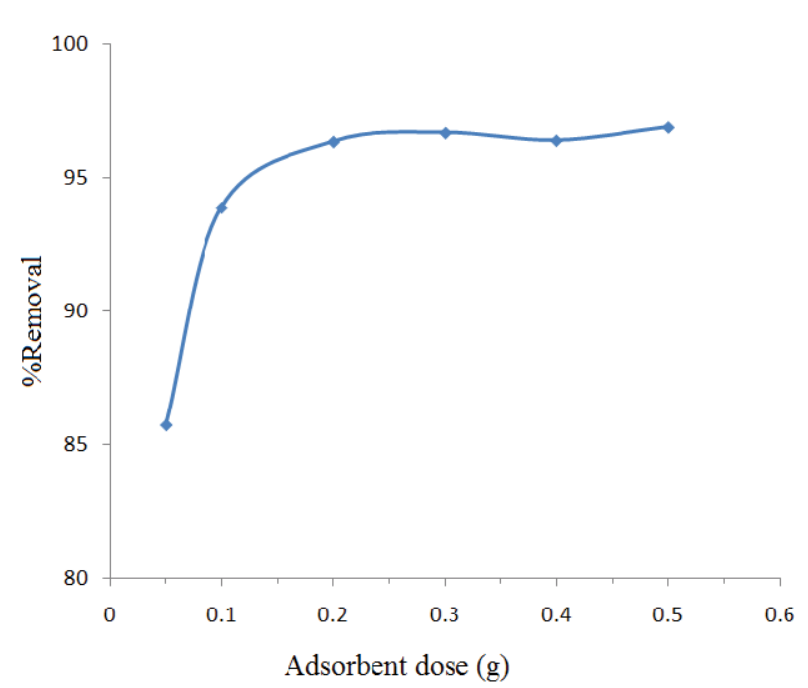

Figure 6: Effect of adsorbent (SCTW) dosage on adsorption of MB (initial MB concentration: $100 \mathrm{mg} / \mathrm{L}$; solution volume: $100 \mathrm{~mL}$, contact time: 120 $\mathrm{min}$; adsorbent dose: $0.05-0.6(\mathrm{~g} / 100 \mathrm{~mL})$, temperature: $298 \mathrm{~K})$.

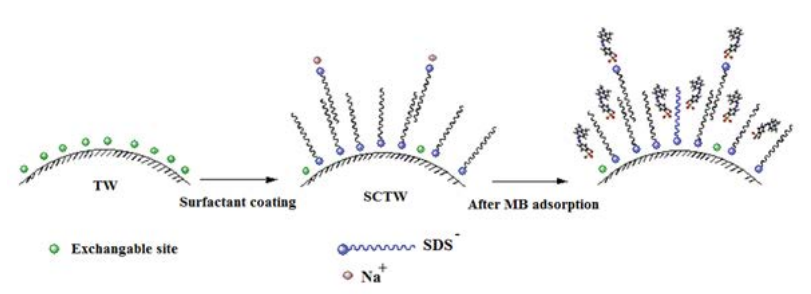

Figure 7: Schematic illustration of proposed mechanisms for MB adsorption onto SCTW.

formation of discrete surface aggregates termed admicelles. Both of these hemimicelle or admicelle regions formed on the surface of oxides are potential adsorbing locations [48]. Another possible mechanism is the hydrocarbons tail group of surfactant may interact with solid surface through hydrophobic-bonding and the head group directed toward the bulk of the solution, so the surface is potential negative or positive. The mechanism was due to adsorption of SDS onto TW surface (Figure 7). The non-polar portion (alkyl) of SDS may interact with TW surface through hydrophobic-bonding and the polar (negative charged) head group directed toward the bulk of the solution, so the surface is potential negative. So there is negative charge onto surface of SCTW and the mechanism of adsorption about MB onto SCTW may include electrostatic interaction or ion-exchange. Also, some of the MB molecules adsorbed onto the SCTW surface through hydrophobic interaction between $\mathrm{MB}$ and hydrocarbon tail of surfactant (Figure 7). We will get more details about it in section 5.10.

\section{Isotherm modeling}

Figure 8 and Table 1 show the fitting parameters for the measured isotherm data for MB adsorption onto SCTW in the nonlinear forms of the Langmuir and Freundlich models. By comparing the correlation coefficients $\mathrm{R}^{2}$, it can be deduced that the experimental equilibrium adsorption data are well described by the Langmuir equation compared with Freundlich model. This suggests the monolayer coverage of the surface of SCTW by MB molecules. The high adsorption capacity in SCTW could be due to the large amount of surfactant on the surface of 

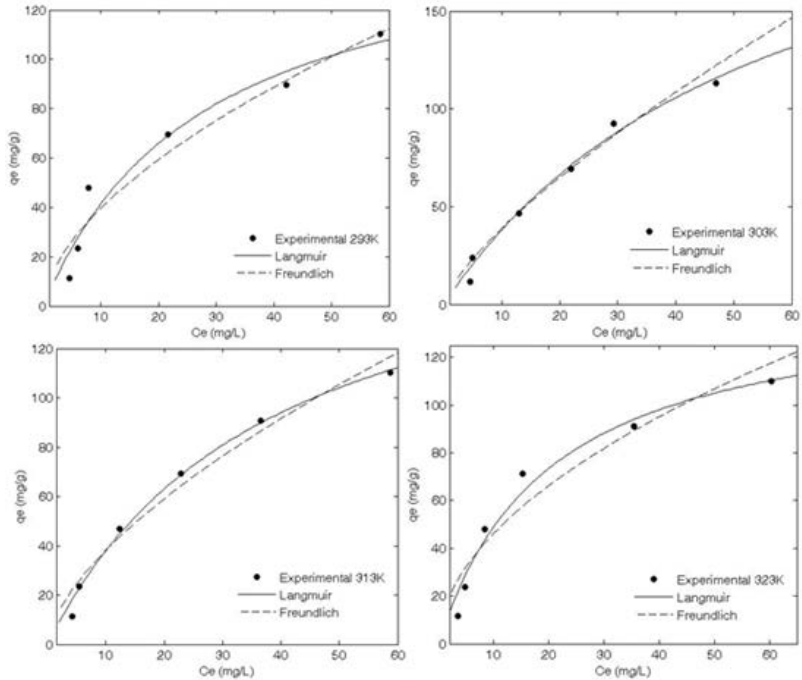

Figure 8: Isotherm plots for MB adsorption onto SCTW at different temperatures.

TW particles, which could result in increasing amounts of negatively charged sites on the surface of TW and finally facilitates the attraction towards the positively dye molecules. Moreover, the $\mathrm{Q}_{\max }$ decreases with an increase in temperature (from $303 \mathrm{~K}$ to $323 \mathrm{~K}$ ), which specifies an exothermic nature ofthe existing process. Through the discussion about isotherm constants, it can be predicted whether an adsorption system is favorable or unfavorable. The essential characteristics of the Langmuir isothermcan be expressed by means of $\mathrm{R}_{\mathrm{L}}$, a dimensionless constant referred to as separation factor or equilibrium parameter $R_{L}$ is defined by:

$$
R_{L}=1 /\left(1+K_{l} C_{0}\right)
$$

Where, $\mathrm{C}_{0}$ is the highest initial dye concentration $(500 \mathrm{mg} / \mathrm{L})$. The parameter suggests the type of isotherm to be irreversible $\left(R_{L}=0\right)$, favorable $\left(0<\mathrm{R}_{\mathrm{L}}<1\right)$, linear $\left(\mathrm{R}_{\mathrm{L}}=1\right)$ or unfavorable $\left(\mathrm{R}_{\mathrm{L}}>1\right)$. As can be seen from Table 1, at all temperatures the $\mathrm{R}_{\mathrm{L}}$ values are between 0 and 1.0 , indicating that the adsorption of MB onto SCTW is favorable.

The Freundlich equation is suitable for homogeneous and heterogeneous surfaces, indicating a multilayer adsorption [49]. The magnitude of the Freundlich constant gives a measure of favorability of adsorption. Values of $\mathrm{n}>1$ represent a favorable adsorption process [43]. For the present study, the value of $n$ also presents the same trend at all the temperatures indicating the favorable nature of adsorption of MB by SCTW. This is in good agreement with the findings regarding to $\mathrm{R}_{\mathrm{L}}$ values.

\section{Adsorption kinetics studies}

The dynamics of the adsorption can be studied by the kinetics of adsorption in terms of the order of the rate constant [50]. The adsorption rate is an important factor for a better choice of material tobe used as an adsorbent; where the adsorbent should have a large adsorption capacity and a fast adsorption rate. Most of adsorption studies used pseudo-first-order and pseudo-second-order models to study the adsorption kinetics. For the pseudo-first-order model, the adsorption rate was expected to be proportional to the first power of concentration, where the adsorption was characterized by diffusion through a boundary. The pseudo-first-order model sometimes does not fit well for the whole range of contact time when it failed theoretically to predict the amount of dye adsorbed and thus deviated from the theory. In that case, the pseudo-second-order equation used was based on the sorption capacity of the solid phase, where the pseudo-secondorder model assumes that chemisorptions may be the rate-controlling step in the adsorption processes [51]. The transient behavior of the MB adsorption process was analyzed by using the pseudo-first and pseudosecond-order kinetic models. Plotting $\ln \left(\mathrm{q}_{\mathrm{e}}, \mathrm{q}^{t}\right)$ against $\mathrm{t}$ permits calculation of $\mathrm{k}_{1}$ (Figure 9a). The rate constants, $\mathrm{k}_{\mathrm{l}}$, evaluated from these plots with the correlation coefficients obtained are listed in Table 2. Plotting $t / q$ against $t$ (Figure $9 b$ ), gives a straight line where $\mathrm{k}_{2}$ can be calculated. Usuallythe best-fit model can be selected based on the linear regression correlation coefficient $\mathrm{R}^{2}$ values. Generally the kinetic adsorption is better represented by pseudo-second-order model for anionic and cationic dye adsorption. The $\mathrm{R}^{2}$ listed (Table 2) for the pseudo-first-order kinetic model was between 0.945 and 0.979 . The $\mathrm{R}^{2}$ values for pseudo-second-order model were 1 , which is higher than the $\mathrm{R}^{2}$ values obtained for the pseudo-first-order model. Therefore, the adsorption kinetics could well be satisfactorily more favorably described bypseudo-second-order kinetic model for MB adsorption onto SCTW.

In adsorption process of dye ion on the solid surface, the dye species migrate towards thesurface of the adsorbent. This type of migration proceeds till the concentration of the adsorbate species, adsorbed, on to the surface of the adsorbent. Once equilibrium is attained, the migration of the solute species from the solutions tops. Under this situation, it is possible to measure the magnitude of the distribution of the solute species between the liquid and solid phases. The magnitude of this kind of distribution is a measure of the efficiency of the chosen adsorbent in the adsorbate species. When a powdered solid adsorbent materialis made in contact with a solution containing dyes, the dyes first migrate from the bulk solution to the surface of the liquid film. This surface exerts a diffusion barrier. This barrier may be very significant or less significant [52]. The involvement of a significant quantum of diffusion barrier indicates the dominant role taken up by the film diffusion in the adsorption process. Furthermore, the rate of an adsorption process is controlled either by external diffusion, internal diffusion or by both types of diffusions. The external diffusion controls the migration of the solute species from the solution to theboundary layer of the liquid phase. However,the internal diffusion controls the transfer of the solute species from the external surface of the adsorbent to the internal surface of the pores of the adsorbent material [53]. It is now well established, that during the adsorption of dye over a porous adsorbent, the following three consecutive steps were taken place [54,55]:

(i) Transport of the ingoing adsorbate ions to external surface of the adsorbent (film diffusion).

(ii) Transport of the adsorbate ions within the pores of the adsorbent except for a small amount of adsorption, which occurs on the external surface (particle diffusion).

(iii) Adsorption of the ingoing adsorbate ions on the interior surface of the adsorbent.

Out of these three processes, the third process is considered to be very fast and is not the rate limiting step in the uptake of organic compounds. The remaining two steps impart the following three possibilities:

Case 1 External transport>internal transport, where rate is governed by particle diffusion. 
Citation: Pirbazari AE, Pargami NR, Ashja N, Emami MS (2015) Surfactant-coated Tea Waste: Preparation, Characterization and its Application for Methylene Blue Adsorption from Aqueous Solution. J Environ Anal Toxicol 5: 310. doi:10.4172/2161-0525.1000310

Page 8 of 11

\begin{tabular}{|c|c|c|c|c|}
\hline \multirow[b]{2}{*}{ Temperature $(\mathrm{K})$} & \multicolumn{4}{|c|}{ Langmuir } \\
\hline & 293 & 303 & 313 & 323 \\
\hline $\mathrm{Q}_{\max }(\mathrm{mg} / \mathrm{g})$ & 158.18 & 256.74 & 184.05 & 146.94 \\
\hline $\mathrm{K}_{\mathrm{L}}(\mathrm{L} / \mathrm{mg})$ & 0.0357 & 0.0175 & 0.0261 & 0.05 \\
\hline $\mathrm{R}_{\mathrm{L}}$ & 0.05305 & 0.10256 & 0.07117 & 0.03846 \\
\hline \multirow[t]{2}{*}{ R2 } & 0.9882 & 0.9945 & 0.9927 & 0.9907 \\
\hline & \multicolumn{4}{|c|}{ Freundlich } \\
\hline Temperature (K) & 293 & 303 & 313 & 323 \\
\hline $\mathrm{n}$ & 1.72 & 1.36 & 1.59 & 1.94 \\
\hline $\mathrm{k}_{\mathrm{F}}(\mathrm{mg} / \mathrm{g})\left(\mathrm{dm}^{3} / \mathrm{mg}\right)^{1 / n}$ & 10.45 & 7.08 & 8.96 & 13.96 \\
\hline R2 & 0.9354 & 0.9732 & 0.9710 & 0.9229 \\
\hline
\end{tabular}

Table 1: Isotherm parameters for MB adsorption onto SCTW.

\begin{tabular}{|c|c|c|c|c|c|c|}
\hline \multirow{2}{*}{$\mathrm{C}_{0}(\mathrm{mg} / \mathrm{L})$} & \multicolumn{3}{|c|}{ pseudo-first order } & \multicolumn{3}{|c|}{ pseudo-second order } \\
\hline & $\mathrm{q}_{\mathrm{e}}(\mathrm{mg} / \mathrm{g})$ & $\mathrm{k}_{1}(1 / \mathrm{min})$ & $\mathrm{R}^{2}$ & $q_{e}(m g / g)$ & $\mathrm{k}_{2}(\mathrm{~g} / \mathrm{mg} \cdot \mathrm{min})$ & $\mathrm{R}^{2}$ \\
\hline 50 & 0.056 & 0.0077 & 0.9569 & 15.53 & 0.1908 & 0.9999 \\
\hline 100 & 0.251 & 0.0129 & 0.9793 & 31.06 & 0.4149 & 0.9999 \\
\hline 200 & 0.796 & 0.023 & 0.9452 & 61.35 & 0.0010 & 0.9999 \\
\hline
\end{tabular}

Table 2: Kinetic parameters for the adsorption of MB onto SCTW based on Lagergren rate equation.

Case 2 External transport<internal transport, where the rate isgoverned by film diffusion.

Case 3 External transport $\approx$ internal transport, which accounts for the transport of the adsorbate ions to the boundary and may not be possible with in a significant rate, which later on gives rise to the formation of a liquid film surrounded by the adsorbent particles with a proper concentration gradient. In order to predict the actual slow step involved in the adsorption process, the kinetic data were further analyzed using the Boyd model given by Eq. (8) [56]

$$
B_{t}=-0.4977-\ln (1-F)
$$

F represents the fraction of solute adsorbed at anytime, $\mathrm{t}(\mathrm{h})$, as calculated using Eq. (9)

$$
F=q_{t} / q_{e}
$$

Where $q_{t}$ and $q_{e}$ are amounts adsorbed after time $t$ and after infinite time (160 min), respectively. The calculated $B_{t}$ values were plotted against time $t(h)$, as shown in Figure 10. The plot of $B_{t} v s$ time distinguishes between the film-diffusion and particle-diffusioncontrolled rates of adsorption. The linear lines for all MB initial concentrations did no pass through the origin and the points were scattered. This indicated that the adsorption of MB on the SCTW was mainly governed by external mass transport where particle diffusion was the ratelimiting step [56].

\section{Adsorption thermodynamics}

In environmental engineering practice, both energy and entropy factors must be considered in order to determine what processes will occur spontaneously [57]. Gibb's free energy change, $\Delta G^{\circ}$, is the fundamental criterion of spontaneity. Reactions occur spontaneously at a given temperature if $\Delta G^{\circ}$ is a negative value. The thermodynamic parameters of $\Delta \mathrm{G}^{\circ}$, enthalpy change, $\Delta \mathrm{H}^{\circ}$, and entropy change, $\Delta S^{\circ}$, for the adsorption processes are calculated using the following equations [57,58].

$$
\Delta G^{\circ}=-R T \ln K_{D}
$$

$K_{\mathrm{D}}$, is given by the following equation:
$K_{D}=q_{e} / C_{e}$

Where $\mathrm{K}_{\mathrm{D}}$ is the distribution coefficient and:

$$
S^{*}=(1-\theta) e^{-(E / R T)}
$$

Where, $R$ is universal gas constant $(8.314 \mathrm{~J} / \mathrm{mol} \mathrm{K})$ and $\mathrm{T}$ is the absolute temperature in $\mathrm{K}$. A plot of $\ln \mathrm{K}_{\mathrm{D}}$ versus $1 / \mathrm{T}$ was found to be linear. The values of $\Delta \mathrm{H}^{\circ}$ and $\Delta S^{\circ}$ were respectively determined from the slope and intercept of the plot. The thermodynamic parameter, $\Delta \mathrm{G}^{\circ}$, is shown in Table $3 . \Delta \mathrm{H}^{\circ}$ and $\Delta \mathrm{S}^{\circ}$ for the sorption process were calculated to be $-0.05 \mathrm{~kJ} / \mathrm{mol}$ and $+3.20 \mathrm{~J} / \mathrm{mol} \mathrm{K}$, respectively. The negative value of $\Delta G^{\circ}$ confirms the feasibility of the process and the spontaneous nature of sorption with a high preference for $\mathrm{MB}$ to adsorb onto SCTW. The value of $\Delta \mathrm{H}^{\circ}$ was negative, indicating that the sorption reaction is exothermic. These values did not indicate strong chemisorptive bond formation between the dye molecules and the adsorbent surface. The positive value of $\Delta S^{0}$ (Table 3 ) shows that the freedom of MB is not too restricted in SCTW confirming a physical adsorption, which is further confirmed by the relatively low values of $\Delta \mathrm{G}^{0}$. Also, the positive $\Delta S^{\circ}$ value reveals increased randomness at the interface of solid and liquid, indicating the accumulation of MB.

The activation energy $\left(\mathrm{E}_{\mathrm{a}}\right)$ was obtained from the slope of plot $\ln$ (1- $\theta$ )against $1 / \mathrm{T}$, where the surface coverage $(\theta)$ was calculated from the relation eqs. (13) [58,59]:

$$
\theta=1-\left(C / C_{0}\right)
$$

Where: $\mathrm{C}_{0}$ and $\mathrm{C}$ are the initial and residual concentration of $\mathrm{MB}$ in solution, respectively $(\mathrm{mg} / \mathrm{L})$.

In order to further support the assertion that physical adsorption is the predominant mechanism, the values of sticking probability $\left(S^{*}\right)$ was estimated from the experimental data. It was calculated using a modified Arrhenius type equation related to surface coverage as expressed in Equation (14) $[58,60]$.

$$
S^{*}=(1-\theta) e^{-\left(E_{a} / R T\right)}
$$


Citation: Pirbazari AE, Pargami NR, Ashja N, Emami MS (2015) Surfactant-coated Tea Waste: Preparation, Characterization and its Application for Methylene Blue Adsorption from Aqueous Solution. J Environ Anal Toxicol 5: 310. doi:10.4172/2161-0525.1000310

Page 9 of 11

\begin{tabular}{|c|c|c|c|c|c|}
\hline \multicolumn{5}{|c|}{ Langmuir isotherm } \\
\hline Temperature $(\mathrm{K})$ & $\Delta \mathrm{G}^{\circ}(\mathrm{kJ} / \mathrm{mol})$ & $\Delta \mathrm{H}^{\circ}(\mathrm{kJ} / \mathrm{mol})$ & $\Delta \mathrm{S}^{\circ}(\mathrm{J} / \mathrm{mol} \mathrm{K})$ & $\mathrm{E}_{\mathrm{a}}(\mathrm{kJ} / \mathrm{mol})$ & \\
\hline 293 & -1.644 & & +3.20 & -0.05 \\
\hline 313 & -1.637 & -0.62 & 0.117 \\
\end{tabular}

Table 3: Thermodynamic parameters for the adsorption of MB onto SCTW.
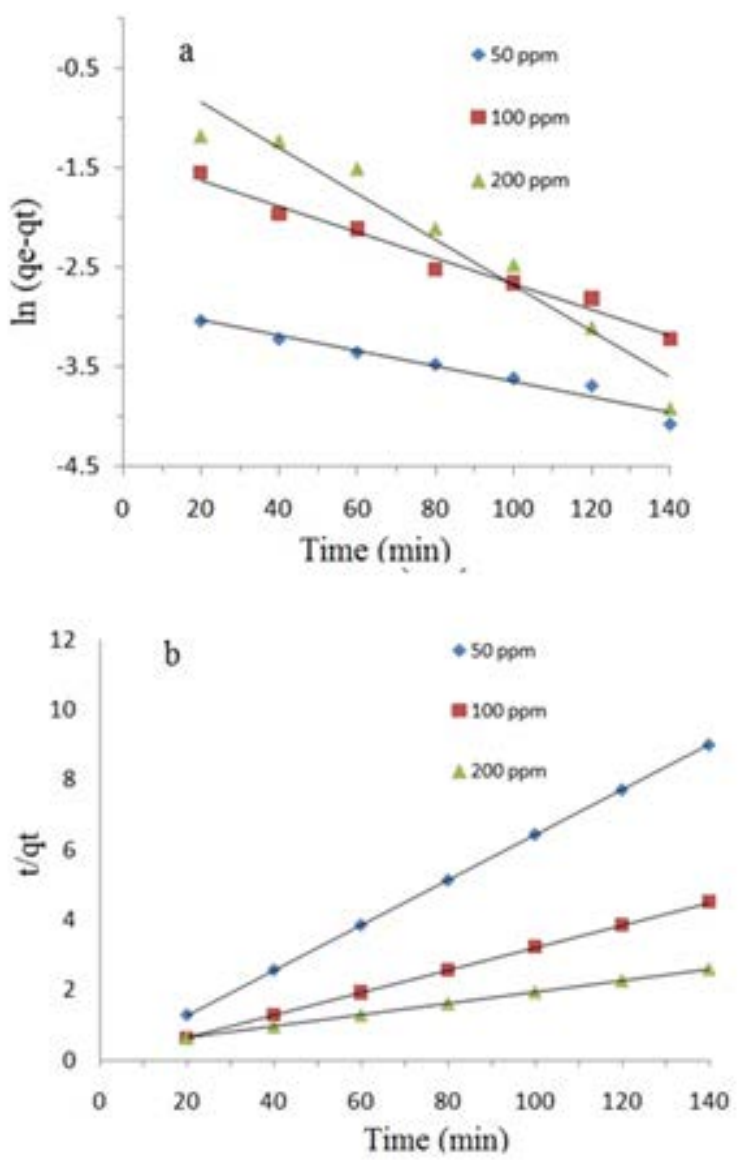

Figure 9: Kinetic models for adsorption of MB onto SCTW.(a) pseudo-firstorder and (b) pseudo-second-order rate equations.

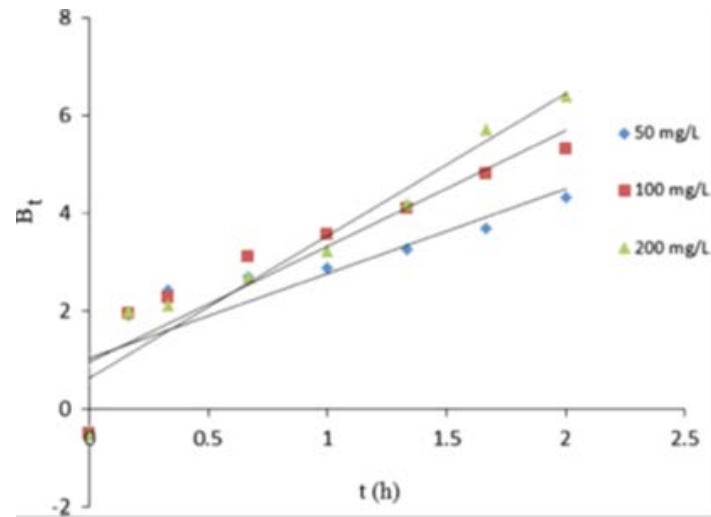

Figure 10: Plot of $B_{t} v s$ time for different initial concentrations of $M B$.
The parameter $S^{*}$ indicates the measure of the potential of an adsorbate to remain on the adsorbent indefinitely. It can be expressed as in Table 3. The effect of temperature on the sticking probability was evaluated throughout the temperature range from 293 to $323 \mathrm{~K}$ by calculating the surface coverage at the various temperatures. The apparent activation energy $\left(\mathrm{E}_{\mathrm{a}}\right)$ and the sticking probability $\left(S^{*}\right)$ are estimated from the plot with reasonable good fit for the $\mathrm{MB}$ on the SCTW. The $\mathrm{E}_{\mathrm{a}}$ values calculated from the slope of the plot were found to $b e-0.05 \mathrm{~kJ} / \mathrm{mol}$. The negative values of $\mathrm{E}_{\mathrm{a}}$ indicate that lower solution temperatures favors MB removal by adsorption onto SCTW and the adsorption process is exothermic in nature. Relatively low values of $\mathrm{E}_{\mathrm{a}}$ suggest that $\mathrm{MB}$ adsorption is a diffusion controlled process. The results as shown in Table 3 indicate that the probability of MB sticking to the SCTWsurface is very high as $0<\mathrm{S}^{*}<1$ for MB (Table 3). These values confirm that, the sorption process is physisorption[60].

\section{Desorption studies of MB}

Desorption studies can help enlightening the mechanism of an adsorption process. If the dye adsorbed onto the adsorbent can be desorbed by water, it can be said that the attachment of the dye onto the adsorbent is by weak bonds. If the strong bases, such as $\mathrm{NaOH}$ can desorbs the dye, it can be said that the attachment of the dye onto the adsorbent is by ion exchange [61]. Hence, neutral distilled water was used in the elution of MB molecules from the SCTW followed by $\mathrm{NaOH}$ solution. The percentage of desorption obtained were $17 \%$ and $20 \%$ for using neutral distilled water and $0.1 \mathrm{~N} \mathrm{NaOH}$ solution, respectively. The fact that the low desorption occurred with distilled water and $\mathrm{NaOH}$ solution suggests that adsorption of $\mathrm{MB}$ onto SCTW carries out significantly by another mechanism. The mode of existence of surfactant molecules on solid surface has been investigated widely [48]. As we mentioned in section 5.6, a possible mechanism is the hydrocarbons tail group of surfactant may interact with solid surface through hydrophobic-bonding and the head group directed toward the bulk of the solution, so the surface is potential negative or positive. Consequently, it can be conceived from the result of desorption by $\mathrm{NaOH}$ that some surfactant molecular arrange in this manner in the research. Here, the above conclusion related to ionexchange mechanism is clearly confirms. Taking all the results that have been discussed above into account, it is proposed that enhanced hydrophobic interaction is the predominant mechanism contributing to the increased MB adsorption on the SCTW, followed by a certain amount of the cationic exchange. For better illustration of the process of adsorption, a suggested adsorption structure was shown in Figure 7.

\section{Cost evaluation of the adsorbent}

Adsorbent cost is important to practicability. Cost of the adsorbent prepared in this work is mainly from use of surfactant. The market price of SDS is about US $\$ 7000$ per metric ton. The cost of the prepared adsorbent is around US $\$ 630$ per metric ton according to the ratio of TW to the surfactant (10:1). The market price of commercial activated carbon is about US $\$ 500-800$ per metric ton. It is clear that the cost of the two adsorbent is similar. Compared with activated carbon, however, SDS modified TW adsorbent has some advantages, such as 
Citation: Pirbazari AE, Pargami NR, Ashja N, Emami MS (2015) Surfactant-coated Tea Waste: Preparation, Characterization and its Application for Methylene Blue Adsorption from Aqueous Solution. J Environ Anal Toxicol 5: 310. doi:10.4172/2161-0525.1000310

Page 10 of 11

simple preparation procedure and low energy consumption, and has good application prospect.

\section{Conclusions}

The results of this investigation show that sodium dodecyle sulfate coated tea waste (SCTW) has excellent adsorption capacity for the removal of methylene blue from aqueous solutions. SEM shows that morphological feature of TW changed after modification. FTIR results suggest that the SDS have been successfully coated the surface of TW. The adsorption isotherm experiment was conducted at different temperatures $(293,303,313$ and $323 \mathrm{~K})$, and it was found that the uptake of $\mathrm{MB}$ decreased with increasing temperature and hence adsorption process is exothermic in nature. The equilibrium data were analyzed by the Langmuir and Freundlich models and the Langmuir model was found to fit the equilibrium data better. The adsorption capacity was found to be $256 \mathrm{mgg}^{-1}$ at $303 \mathrm{~K}$. The pseudo-second order kinetic model agrees very well with the dynamic behavior for the adsorption of $\mathrm{MB}$ onto surfactant modified tea waste. In addition, various thermodynamic parameters such as changes in enthalpy, entropy, and the Gibbs free energy were calculated, showing adsorption to be an exothermic process. The desorption studies implied that the hydrophobic interaction and cationic exchange models controlled simultaneously during the adsorption process, but the former is a dominant mechanism. The developed SCTW not only has demonstrated higher adsorption efficiency and fast kinetics but also have shown additional benefits like cost-effectiveness and environmental-friendliness. It can be concluded to be a promising advanced adsorbent in environmental pollution cleanup.

\section{Acknowledgments} Tehran.

The authors wish to acknowledge the financial support of the University of

\section{References}

1. (2000) WHO, UNICEF, Global Water Supply and Sanitation Assessment 2000 Report, WHO, Geneva.

2. Bhatnagar A, Sillanpää M (2010) Utilization of agro-industrial and municipal waste materials as potential adsorbents for water treatment-A review. Chem Eng J 157: 277-296.

3. Gupta VK, Suhas (2009) Application of low-cost adsorbents for dye removal-A review. J Environ Manage. 90: 2313-2342.

4. Pearce Cl, Lloyd JR, Guthrie JT (2003) The removal of colour from textile wastewater using whole bacterial cells: A review. Dyes Pigm 58: 179-196.

5. McMullan G, Meehan C, Conneely A, Kirby N, Robinson T, et al. (2001) Microbial decolourisation and degradation of textile dyes. Appl Microbio Biotechnol 56: 81-87.

6. Moussavi G, Mahmoudi M (2009) Removal of azo and anthraquinone reactive dyes from industrial waste waters using $\mathrm{MgO}$ nanoparticles. J Hazard Mater 168: 806-812.

7. Christie RM (2007) Environmental Aspects of Textile Dyeing, Woodhead, Boca Raton, Cambridge, England.

8. Nabil GM, El-Mallah NM, Mahmoud ME (2014) Enhanced decolorization of reactive black 5 dye by active carbon sorbent-immobilized-cationic surfactant (AC-CS). J Industrial and Eng Chem 20: 994-1002.

9. Kumar KV, Ramamurthi V, Sivanesan S (2005) Modeling the mechanism involvedduring the sorption of methylene blue onto fly ash. J Colloid Interf Sci 284: 14-21.

10. Al-Degs Y, Khraisheh MAM, Allen SJ, Ahmad MNA (2001) Sorption behavior of cationic and anionic dyes from aqueous solution on different types of activated carbons. Sep Sci Technol 36: 91-102.

11. Mahmoud ME, Al-Bishri HM (2011) Supported hydrophobic ionic liquid on nano-silica for adsorption of lead. Chem Eng J 166: 157-167.
12. Shafeeyan MS, AshriWan Daud WM, Houshmand AH, Shamiri A (2010) A review on surface modification of activated carbon for carbon dioxide adsorption. J Anal Appl Pyrol 89: 143-151.

13. Panuccio MR, Sorgonà A, Rizzo M, Cacco G (2009) Cadmium adsorption on vermiculite, zeolite and pumice:batch experimental studies. J Environ Manage 90: 364-374

14. Hizal J, Apak R (2006) Modeling of cadmium(II) adsorption on kaolinite-based clays in the absence and presence of humic acid. Appl Clay Sci 32: 232-244.

15. Bamgbose JT, Adewuyi S, Bamgbose O, Adetoye AA (2010) Adsorption kinetics of cadmium and lead by chitosan. Afr J Biotechnol 9: 2560-2565.

16. Shin EW, Karthikeyan KG, Tshabalala MA (2007) Adsorption mechanism of cadmium on juniper bark and wood. Bio resource Technol 98: 588-594.

17. Sevgi $\mathrm{K}$ (2009) Adsorption of $\mathrm{Cd}(\mathrm{II}), \mathrm{Cr}$ (III) and $\mathrm{Mn}$ (II) on natural sepiolite. Desalination 244: 24-30.

18. Panda GC, Das SK, Guha AK (2008) Biosorption of cadmium and nickel by functionalized husk of Lathyrussativus. Colloids Surf B Biointerfaces 62: 173179 .

19. Robinson T, Chandran B, Nigam P (2002) Effect of pretreatment of three waste residues, wheat straw, corn cob sand barley husks on dye adsorption. Bioresour Technol 85: 119-124.

20. Gurses A, Karaca S, Dogar C, Bayrak R, Acikyildiz A, et al. (2004) Determination of adsorptive properties of clay/water system:Methyleneblue sorption. J Colloid Interface Sci 269: 310-314.

21. Mohammed MA, Shitu A, Ibrahim A (2014) Removal of methylene blue using low cost adsorbent: a review. Res J Chem Sci 4: 91-102.

22. Oladipo MA, Bello IA, Adeoye DO, Abdulsalam KA, Giwa AA (2013) Sorptive removal of dyes from aqueous solution: A review. Adv Environ Biol 7: 3311 3327.

23. MohdSalleh MA, Khalid Mahmoud D, Wan Abdul Karim WA, Idris A (2011) Cationic and anionic dye adsorption by agricultural solid wastes:a comprehensive review. Desalination 280: 1-13.

24. Gaballah I, Goy D, Allain E, Kilbertus G, Thauront J (1997) Recovery of copper through decontamination of synthetic solutions using modified barks. Metal Mater Trans B 28: 13-23.

25. Crini G, Badot PM (2008) Application of chitosan, a natural aminopolysaccharide for dye removal from aqueous solutions by adsorption processes using batch studies:a review of recent literature. Prog Polym Sci 33: 399-447.

26. Hameed BH (2009) Spent tea leaves: Anew non-conventional and low-cost adsorbent for removal of basic dye from aqueous solutions. J Hazard Mater 161: 753-759.

27. García-Río L, Hervella P, Mejuto JC, Parajò M (2007) Spectroscopic and kinetic investigation of the interaction between crystal violet and sodium dodecyl sulfate. Chem Phys 335: 164-176.

28. Simončič B, Kert M (2002) A study of anionic dye-cationic surfactant interactions in mixtures of cationic and nonionic surfactants. Dyes Pigm 54: 221-237.

29. Khobragade MU, Anjali Pal (2014) Investigation on the adsorption of Mn(II) on surfactant-modified alumina: Batch and column studies. J Environ Chem Eng 2: 2295-2305.

30. Jin X, Yu B, Chen Z, Arocena JM, Thring RW (2014) Adsorption of orange II dye in aqueous solution onto surfactant-coated zeolite: Characterization kinetic and thermodynamic studies. J Colloid and Inter Sci 435:15-20.

31. Chen W, Pan L, Chen L, Yu Z, Wang Q, et al. (2014) Comparison of EDTA and SDS as potential surface impregnation agents for lead adsorption by activated carbon. Appl Surf Sci 309: 38-45.

32. Chatterjee S, Lee DS, Lee MW, Woo SH (2009) Congo red adsorption from aqueous solutions by using chitosan hydrogel beads impregnated with nonionic or anionic surfactant. Bioresour Technol 100: 3862-3868.

33. Chen H, Zhao J, Wu J, Dai G (2011) Isotherm, thermodynamic, kinetics and adsorption mechanism studies of methylorange by surfactant modified silkworm exuviae. J Hazard Mater 192: 246- 254.

34. Liu Y, Liu YJ (2008) Biosorption isotherms, kinetics and thermodynamics. Sep PurifTechnol61: 229-242.

35. Lagergren $S$ (1898) About the theory of so-called adsorption of soluble 
Citation: Pirbazari AE, Pargami NR, Ashja N, Emami MS (2015) Surfactant-coated Tea Waste: Preparation, Characterization and its Application for Methylene Blue Adsorption from Aqueous Solution. J Environ Anal Toxicol 5: 310. doi:10.4172/2161-0525.1000310

substances. KungligaSvenskaVetenskapsakademiens, Handlingar 24: 1-39.

36. Gnanasambandam R, Protor A (2000) Determination of pectin degree of esterification by diffuse reflectance. Fourier transform infrared spectroscopy - quantitative evaluation of uronic acid and acetamidodeoxyhexose moieties. Food Chem 68: 327-332.

37. Sidiras D, Batzias F, Schroeder E, Ranjan R, Tsapatsis M (2011) Dye adsorption on auto hydrolyzed pine sawdust in batch and fixed-bed systems. Chem Eng J 171: 883-896.

38. Nadeem M, Shabbir M, Abdullah MA, Shah SS, McKay G (2009) Sorption of cadmium from aqueous solution by surfactant-modifiedcarbon adsorbents. Chem Eng J 148: 365-370.

39. Nasuha N, Hameed BH, Din AT (2010) Rejected tea as a potential low-cost adsorbent for the removal of methylene blue J Hazard Mater 175: 126-132.

40. Poghossian AA (1997) Determination of the $\mathrm{pH}_{\text {zzc }}$ of insulators surface from capacitance-voltage characteristics of MIS and EIS structures. Sens Actuator B Chem 44: 551-553.

41. Radovic R, Silva IF, Ume JI, Menendez JA, Leon CA, et al. (1997) An experimental and theoretical study of the adsorption of aromatics possessing electron-withdrawing and electron-donating functional groups by chemically modified activated carbons. Carbon 35: 1339-1348.

42. Savova D, Petrov N, Yardim MF, Ekinci E, Budinova T, et al. (2003) The influence of the texture and surface properties of carbon adsorbents obtained from biomass products on the adsorption of manganese ions from aqueous solution. Carbon 41: 1897-1903.

43. Chakraborty S, Chowdhury S, Saha PD (2011) Adsorption of crystal violet from aqueous solution onto $\mathrm{NaOH}-$ modified rice husk. Carbohyd Polym 86: 15331541.

44. Ahmad R (2009) Studies on adsorption of crystal violet dye from aqueous solution onto coniferous pinus bark powder (CPBP). J Hazard Mater171: 767773.

45. Saeed A, Sharif M, Iqbal M (2010) Application potential of grape fruit peel as dye sorbent: kinetics, equilibrium and mechanism of crystal violet adsorption. $J$ Hazard Mater 179: 564-572.

46. Aksakal O, Ucun H (2010) Equilibrium, kinetic and thermodynamic studies of the biosorption of textile dye (ReactiveRed195) onto Pinussylvestris L. J Hazard Mater 181: 666-672.

47. Crini G, Peindy HN, Gimbert F, Robert C (2007) Removal of C.I.Basic Green 4 (Malachite Green) from aqueous solutions by adsorption using cyclodextrinbased adsorbent :kinetic and equilibrium studies. Sep Purif Technol 53: 97-110.
48. Ariapad A, Zanjanchi MA, Arvand M (2012) Efficient removal of anionic surfactant using partial template-containing MCM-41. Desalination 284: 142 149.

49. Igwe JC, Abia AA (2003) Maize coband huskas adsorbent for removal $\mathrm{Cd}, \mathrm{Pb}$ and $\mathrm{Zn}$ ions from wastewater. Phys Sci 2: 83-94.

50. Gómez V, Larrechi MS, Callao MP (2007) Kinetic and adsorption study of acid dye removal using activated carbon. Chemosphere 69: 1151-1158.

51. Aksu Z (2005) Application of biosorption for the removal of organic pollutants: a review. Proc Biochem 40: 997-1026.

52. Gupta VK, Mittal A, Gajbe V (2005) Adsorption and desorption studies of a water soluble dye,QuinolineYellow, using waste materials. J Colloid Interface Sci 284: 89-98.

53. Gupta VK, Ali I, Suhas, Mohan D (2003) Equilibrium uptake and sorption dynamics for the removal of a basic dye(basic red) using low-cost adsorbents. J Colloid Interface Sci 265: 257-264.

54. Crank I (1975) The mathematics of diffusion, (2ndedn) Clarendon, Oxford.

55. Weber WJ, Morris JC (1963) Kinetics of adsorption on carbon from solution. $J$ Sanit Eng Div 89: 31-60.

56. Tan IAW, Hameed BH (2010) Adsorption isotherms,thermodynamics and desorption studies of basic dye on activated carbon derived from oil palm empty fruit bunch. J Appl Sci 10: 2565-2571.

57. Ho YS (2006) Isotherms for the sorption of lead onto peat: comparison of linear and non-linear rmethods Pol J Environ Stud 15: 81-86.

58. Butt HJ, Graf K, Kappl M (2003) Physics and Chemistry of Interfaces, WILEY$\mathrm{VCH}$ Verlag $\mathrm{GmbH}$ and Co.KGaA, Weinheim.

59. Bulgariu L, Bulgariu D, Macoveanu M (2008) Equilibrium study of $\mathrm{Pb}(\mathrm{II})$ and $\mathrm{Hg}$ (II )sorption from aqueous solution by moss peat. Environ Eng Manag $\mathrm{J} 7$ : 511-516.

60. JnrHorsfall M, Spiff Al (2005) Effects of temperature on the sorption of $\mathrm{Pb2+}$ and $\mathrm{Cd} 2+$ from aqueous. Electron J Biotechnol 8: 162-169.

61. Mall ID, Srivastava VC, Kumar GVA, Mishra IM (2006) Characterization and utilization of mesoporous fertilizer plant waste carbon for adsorptive removal of dyes from aqueous solution. Colloids Surf A: Physicochem Eng Asp 278: 175-187. 